\title{
CONCEITO ESTÉTICO DE DIREITO
}

\author{
[ AESTHETIC CONCEPT OF LAW ]
}

\author{
Luis Satie * \\ Ministério da Educação, MEC, Brasil
}

\begin{abstract}
Resumo: O direito romano é lembrado, geralmente, por sua fase do dominato, que serviu de modelo para o direito privado do século XIX, em que os anseios imperialistas dos antigos entraram em conjunção com o estágio triunfante do modelo burguês de mundo. Não obstante, a era contemporânea exige mais uma vez o retorno ao passado do direito romano, dessa vez para resgatar e atualizar seu componente grego ou republicano, condição de possibilidade para que o direito se oriente pela razão sensível, pela aesthesis.
\end{abstract}

Palavras-chave: Direito romano; Ética; Aristóteles; Estética
ABSTRACT: Roman law is generally remembered for its dominato phase, which served as a model for nineteenth-century private law, in which the imperialist longings of the ancients came in conjunction with the triumphant stage of the bourgeois model of the world. Nevertheless, the contemporary era demands once again the return to the past of Roman law, this time to rescue and update its Greek or republican component, a condition of possibility for the right to be guided by sensible reason, by aesthesis.

KEYwORDS: Roman law; Ethics; Aristotle; Aesthetics

\section{INTRODUÇÃo}

\author{
$D$, 50, 17, 202: "Toda definição \\ do direito é aleatória, presta-se a \\ ser refutada".
}

\footnotetext{
$\mathrm{O}$ s tempos mudaram. O conceito de direito também. Não que tenhamos que ignorar a tradição, como se fosse possível continuar a pensar ex nihilo. $\mathrm{O}$ novo conceito, pelo contrário, exsurge a partir de uma releitura do velho, como reminiscência do que não pôde ter sido, para lembramos de uma fórmula metodológica de Benjamin. Trata-se aqui, sim, de voltarmos às origens, de auscultar novamente o gênio jurídico romano, mas, sob o olhar grego. Com esse olhar trágico, é possível trazer de volta o caso concreto para o âmbito da faculdade de julgar, despertando-a de seu sono dogmático. Sono esse, causado pelo julgamento lógico determinante, que aciona automaticamente a guilhotina do silogismo da norma sobre o caso, sem permitir que as
} dores do objeto apareçam. 
Referir o direito romano em pleno século XXI não é uma tarefa fácil, devido ao risco de cairmos seja no exotismo, no historicismo ou no anacronismo. No exotismo, se ficarmos em busca das curiosidades do mundo antigo, contentando-nos com a descrição mecânica e anedótica de fatos e personagens. No historicismo, se nos preocuparmos apenas com a cronologia e classificação das fases históricas, na perspectiva de identificar as causas que provocaram a passagem de um momento para outro. No anacronismo, se interpretarmos as instituições romanas do mundo antigo com categorias da modernidade burguesa.

Nesse passo, ao mesmo tempo em que evitaremos os três obstáculos referidos acima, essa exposição do direito romano - enquanto tributário da ética aristotélica e do espírito trágico dos gregos - pode ser considerada a experimenta crucis das categorias da teoria estética do direito ${ }^{1}$, uma teoria bastante útil para o estudo crítico das formas jurídicas em seu devir. Com efeito, toda forma jurídica traz em seu corpus uma condensação de relações de força que a põe em movimento, sem necessariamente conduzi-la a uma síntese. Esse aspecto agônico, e não uma harmonia pré-estabelecida, é o conteúdo de verdade da forma jurídica. Pois bem, essa estrutura monádica contraditória e tensa - está presente no direito romano, como mostraremos a seguir.

\section{A HERANÇA GREgA}

Segundo Michel Villey², do século XII ao século XVIII o estudo do Corpus Juris Civilis e da literatura jurídica romana era a base da formação dos juristas franceses. Aos poucos, do século XIX ao Século XX, sucessivas reformas nos programas universitários foram eliminando o direito romano dos cursos, a ponto de a Universidade de Paris chegar a substituir romanistas aposentados por economistas.

Para Villey, a transformação da história em ciência no século XIX foi a grande responsável por esse malogro. Vindo principalmente da Alemanha, a ideia de objetividade e neutralidade diante dos fatos, de acordo com o modelo das ciências físicas, passa a impregnar a abordagem histórica. Esta passa então de crônica, enquete de fatos e personagens, ou de plantas e animais, ao estatuto de uma ciência experimental, com método rigoroso e objeto especializado.

Mas qual é o objeto dessa ciência histórica? O passado, o factum, o já feito. Para estudar o passado por ele mesmo, com objetividade e neutralidade, os historiadores cientistas queriam encontrar leis históricas, sem as quais a história não poderia se arvorar propriamente como ciência. Seguindo esse paradigma, os romanistas do século XIX queriam descobrir as causas que determinaram o movimento histórico, que provocaram a passagem do direito romano arcaico para o período clássico, deste para o pós-clássico e deste para o bizantino.

Ora, como alerta Jean-Marie Carbasse ${ }^{3}$, o direito não é uma ciência exata, pois em seu domínio as mesmas causas não produzem sempre os mesmos efeitos. $\mathrm{O}$ direito não é regido pelo princípio da causalidade, princípio próprio das ciências físiconaturais. O direito se orienta pela ideia de liberdade, seu objeto não é o estudo das coisas, mas a própria convivência humana.

Nesse sentido, no afã de encontrar normas gerais, uma visão cientificista do direito romano seria incapaz de perceber a relação entre o geral e o particular estabelecida principalmente no período clássico, devido às influências da filosofia grega, propriamente da ética de Aristóteles.

Isso porque, para os romanos da era republicana, o direito não pode reduzir-se ao conhecimento técnico de regras gerais, fixadas através da memória: ele é para os antigos sobretudo uma arte, um savoir-faire, que exige sobretudo inteligência e sutileza, razão e sensibilidade. 
Preocupados em encontrar um ponto de apoio para explicar a mecânica dessa ars jurídica, os romanistas dos séculos XIX e XX fracassaram na apreensão filosófica desse savoir-faire. Ademais, os manuais de direito romano são repletos de categorias modernas como direito subjetivo, direito objetivo, contrato, propriedade, etc., tornando ainda mais suspeito seu modo de tratar a matéria, ao deixar de lado a estrutura da linguagem greco-romana antiga.

$\mathrm{Na}$ ânsia de captar o direito romano como um sistema fechado, os romanistas transplantaram o autoritarismo da fase imperial de Roma para a fase republicana, onde o sistema jurídico era aberto, devido à prudência com que os casos particulares eram tratados.

O direito como ars da Roma clássica não é o direito como scientia da Roma decadente, o qual foi herdado pelo catolicismo e pelo direito moderno da Europa continental. Se, no plano político, o direito republicano foi sufocado pelo direito imperial, da mesma forma, no plano filosófico, a concepção aristotélica do direito foi eliminada pelo positivismo cientificista do século XIX.

Contradizendo-se com sua afirmação de que o direito não é uma ciência exata, para Carbasse, em seu Manuel d'introduction historique au droit, existe uma estreita relação entre a estrutura dos sistemas jurídicos e a lógica formal que o constitui, sendo a contradição a primeira inimiga do jurista.

Para demonstrar essa ideia, Carbasse faz uma pequena digressão etimológica. Assim, Direito vem de directum, o contrário de tortum. Em inglês, tort significa dano. Os vocábulos right em inglês e recht em alemão derivam da mesma raiz indo-europeia, que está em directum.

Esta mesma raiz se encontra em regula, que originou régua e regra. Da mesma forma, ordo indica classe, ordem, linha. O que está fora de ordem é extra ordinem e deve por-se em ordem mediante uma ordem. A palavra Estado, por sua vez, contém a raiz latina que indica estabilidade e permanência. Arremata ainda Carbasse:

À chaque époque [...] les diverses manifestations du droit forment un système : un ensemble cohérent. [...] Il importe donc, pour bien comprendre chaque "moment" du droit, de ne pas briser cette cohérence, et d'en faire une présentation d'ensemble. ${ }^{4}$

No entanto, segundo Villey, esse dispositivo etimológico autoritário, inimigo do erro e da crítica, e, portanto da liberdade, não goza do estatuto da universalidade: é apenas um legs da era imperial do direito romano, base do direito medieval e moderno. Sobre este último, afirma Villey que "[...] sa fonction fut de légitimer, sous le capitalisme libéral, d'excessives inégalités, qui se perpétuent en de nombreuses régions du globe, et, diversement accentué selon les pays et les époques, l'asservissement au Pouvoir". 5

Segundo Villey, em contraposição ao conceito autoritário de directum, a primeira geração republicana de jurisconsultos romanos - como Quintus Mucius Scaevola, Servius Sulpicius, liderados por Cícero e influenciados pela cultura grega - tratou de conferir ao direito a forma de uma arte organizada, a partir de um pequeno número de princípios. Para esse fim, aduz Villey, Cícero em De oratore recorreu à dialética, categoria filosófica grega que significa a arte de distinguir e definir os sentidos precisos de termos gerais da linguagem. Como um aristotélico, Cícero procurou definir o direito mediante a definição mesma de sua finalidade: "sit ergo in jure civili finis hic: legitimae atque usitatae in rebus causisque civium aequabilitatis conservatio"6.

Destarte, uma batalha etimológica não inocente já se trava na apreensão do conceito de direito. A ideia de justa proporção, derivada da ética de Aristóteles, remete à ideia de jus e não de directum. Como nota Villey, jus deriva de justitia: jus a justitia appellatum, expressão contida já nas primeiras linhas do Digesto. 
Assim, a lição de Villey vai de encontro a não poucos romanistas modernos, pois jus não vem de jussum, de jubeo, primeira pessoa do singular do verbo ordenar (jubere). Nesse erro incorre, por exemplo, Carbasse, que acaba forçando uma identificação ideológica entre jus e as leis estatais, produtos do comando do Estado. Afirma Villey que, no latim clássico, jus não indica comando ou ordem, mas o mesmo que dikaion, que significa justo em grego.

\section{Conceito de Direito em Aristóteles}

Segundo Villey, numa direção oposta ao idealismo platônico e suas derivações cristãs, Aristóteles encontrou a ideia de justiça na própria realidade, ou seja, na análise dos usos e costumes praticados. Para isso, Aristóteles se propôs a apreender os fins para onde apontam os comportamentos humanos. Mas como atingir essa realidade de modo imanente? Mediante o estudo da linguagem popular. É o que ocorre no livro V de Ética à Nicômaco ${ }^{7}$, onde Aristóteles analisou os vocábulos justiça (dikaiosunè), e injustiça, (adikia).

Aristóteles verificou então dois usos populares do vocábulo justiça, um uso geral e um uso particular. Segundo o primeiro, justiça é o que aponta para a ordem natural das coisas, coincidindo com a ideia de belo ou de harmonia. Nesse sentido, justo é o homem que age de acordo com a ordem cósmica, ocupando o lugar que lhe foi naturalmente destacado. Mas, como ressalta Villey, essa ideia geral de justiça não é muito profícua, pois ela não distingue, não identifica os comportamentos específicos dos homens. De outra parte, segundo o conceito particular de justiça, homem justo é aquele que só goza do que é seu, nem mais nem menos do que isso, de acordo com a partilha feita pela comunidade, que participa da ordem universal.

Portanto, se o primeiro uso está para a dikaiosunè, uma espécie de direito indeterminado, o segundo está para o dikaion, o direito como medida determinada de algo finito, a saber, a justa proporção que cabe a cada particular, definida pela ordem social em que está inserido, por meio do juiz, Dikastès. Enquanto medida estabelecida pela comunidade, o direito como justiça particular é, por conseguinte, um atributo natural da política, to dikaion politikon.

Devido a esse caráter político, não pode haver direito sem juízes, um terceiro desinteressado, constituído pela polis, para que a justa proporção seja obedecida entre os particulares. Essa é a razão pela qual Michel Villey não concorda com os que defendem a existência de um direito familiar ou internacional na antiguidade grecoromana, pois nessas esferas não havia lugar para a figura de um terceiro desinteressado no uso da razão jurídica.

Mas o que é mesmo o direito, to dikaion, para Aristóteles? Aos olhos de Michel Villey, interpretando o Livro $\mathrm{V}$ de Ética à Nicômaco, o direito é formado por três atributos. Isto é, o direito é ao mesmo tempo um objeto, uma proporção e um meio entre dois extremos. Vejamos cada um deles.

\section{1) O direito é um objeto exterior ao homem}

O direito não é uma abstração, é uma res, uma res justa, o que é justo, id quod justum est. E o que é esse justo? A justa partilha de bens e responsabilidades em uma comunidade. A comunidade não se sustenta sem a política, e esta é constituída pela intersubjetividade, pela relação justa entre cidadãos.

Assim, o direito é uma relação justa entre pessoas. $\mathrm{O}$ direito não se confunde, por conseguinte, com um conjunto de textos, com o que os modernos chamam de direito objetivo, isto é, um conjunto de regras de conduta. Ora, direito é ato justo, é 
partilha, não é potência ou intenção subjetiva.

O dikaion não se confunde também com o conceito de direito subjetivo do liberalismo, uma vez que, para Aristóteles, de uma parte, nenhum indivíduo tem poder de usar arbitrariamente da parte que lhe cabe; de outra parte, ninguém pode exigir da comunidade vantagens sem assumir obrigações. Isso torna a concepção aristotélica incompatível com a ideia moderna de direitos humanos. Como nota Villey:

Si le droit est chose ou part de chose, il ne se confond point à une 'liberté'; au surplus la 'part' de chacun constitue toujours um mélange d'actif e de passif; à chaque fois qu'un citoyen se voit attribuer une propriété, il en supporte aussi les charges. ${ }^{8}$

\section{2) $O$ direito é uma proporção}

Como analogon, o direito que cabe a cada um não é exatamente o mesmo. Nota Villey que a igualdade em grego, to ison, corresponde à ideia de aequum, aequitas, medida adequada. Nesse sentido, o que é igual comporta o diferente, de acordo com a repartição universal refletida na organização da polis. Segundo Aristóteles, essa justa proporção pode ser alcançada mediante distribuições e comutações.

Assinala Villey que tanto a distribuição quanto a comutação não são operadas pelos juízes, razão pela qual traduzir essas expressões, como o fez a escolástica, por justiça distributiva e justiça comutativa é um equívoco. Com efeito, segundo Villey, a distribuição, dikaion en tais dianomais, é anterior à figura do juiz; e a comutação, dikaion en tois sunallagmasin, é operada pelos comerciantes.

Para Villey Aristóteles entende por distribuição a relação entre a quantidade de bens e funções a serem repartidos e as qualidades das pessoas. Já por comutação, Aristóteles designa ora uma troca involuntária, akousia - quando o delito é trocado por uma punição ou por uma reparação pecuniária - ora uma troca voluntária, ekousia, que é a troca contratual propriamente dita. Todavia, tanto na akousia quanto na ekousia, deve-se observar a particularidade do objeto de troca. Aristóteles, ao chamar a atenção para as diferenças entre as coisas a serem intercambiadas, rejeita a ideia de igualdade aritmética como base do princípio de equivalência nos dois casos. Nesse sentido, tanto a ideia de "olho por olho, dente por dente" do Talião, como aquela de troca simples de coisas exatamente iguais são refutadas pela ética do estagirita.

Enquanto justa proporção fundada na diferença entre coisas e pessoas, a concepção de direito em Aristóteles se afasta da ideia moderna de igualdade. Dessa forma, podemos concluir com Villey que: "Au total, les droits reconnus aux diverses personnes seront inégaux. Plus la justice en s'affinant s'approche de son terme, l'équité parfaite [..], plus elle aura chance d'aboutir à l'inégalité des droits". ${ }^{9}$ 3) $\mathrm{O}$ direito é um meio entre dois extremos

Como meson, o direito é produto da dialética, da arte de confrontar posições contraditórias, levando em conta a verdade de cada uma delas. Por isso, esse meio não é uma medida exata, mas um justo meio, uma medida da razão a posteriori, após o debate judiciário, no qual tanto a escuta sincera e desinteressada dos interlocutores quanto a observação do contexto que envolve o litígio é o caminho mais seguro para a sentença. Nas palavras de Villey:

Selon l'analyse d'Aristote, le droit se découvre par observation de la réalité sociale, et confrontation de points de vue divers sur cette réalité, parce que le droit, objet de la justice au sens particulier du mot, est précisément ce milieu, la bonne proportion des choses partagées entre membres du groupe politique. ${ }^{10}$ 
Isto posto, estamos em condições de voltar a Roma clássica, a fim de compreendermos a sua concepção de direito, que não é outra senão uma tradução e, ao mesmo tempo, um desenvolvimento da ética jurídica de Aristóteles.

\section{IV. A ARS JURIS ROMANA}

Seguindo o caminho de Aristóteles, Cícero, em De oratore, se coloca a tarefa de, a seu modo, definir a arte jurídica. Definir significa para Cícero, como para Aristóteles, apreender a finalidade de algo, a partir da linguagem popular empregada no cotidiano da cidade antiga. Cícero, como vimos acima, chega à seguinte definição: "Sit ergo in jure civili finis hic: legitimae atque usitatae in rebus causisque civium aequabilitatis conservatio". Vejamos de perto essa definição com a ajuda de Michel Villey.

\section{1) O direito é político, jus civile}

O direito é um atributo da política, da polis grega ou da civitas romana. Nesse sentido, é um enorme equívoco de muitos manuais referir-se ao direito romano como introdução aos códigos civis modernos, como apêndice do direito privado ${ }^{11}$.

O mesmo equívoco se repete com relação aos manuais de direito internacional, que veem o direito romano como precursor do direito das gentes. Ora, não há direito onde não há possibilidade da existência da figura política de um juiz, dikastès, designado pela comunidade para encontrar a justiça no caso concreto. Não é o caso do direito de família ou do direito internacional, ou jus gentium. Segundo Villey, jus civile é a tradução latina de dikaion politikon. Em suma: o direito ou é político, com a finalidade de construir o bem estar comunitário dos cidadãos, ou não é direito. Afastada então a concepção individualista do direito romano, que tanto serviu para legitimar interesses burgueses, principalmente a partir do século XIX.

\section{2) $O$ direito é equidade, aequabilitas}

O termo aequitas ou aequum traduz a ideia grega de ison ou analogon, uma espécie de igualdade proporcional, não aritmética, levando em conta a qualidade das pessoas no momento da partilha dos bens jurídicos.

Temos aqui uma visão oposta ao conceito abstrato de igualdade dos modernos, que funciona mais como um simulacro ideológico para esconder, debaixo do tapete da luxúria e da ostentação de uma minoria, os elevados índices da miséria social e econômica das populações do globo.

\section{3) O direito é in rebus, coisa corpórea e incorpórea}

O direito não é uma abstração, são bens materiais ou a própria responsabilidade dos cidadãos para com a comunidade. Dessa maneira, no mundo real as pessoas ou têm direito e possuem bens, direitos e obrigações, ou não têm direito e não os possuem.

Se, por exemplo, dois terços da população do mundo vive abaixo das condições de vida mínima, não têm, por conseguinte, nenhum direito, sendo a ideia de direitos humanos apenas uma abstração, um não direito. 
O direito só se realiza no debate sobre pontos controversos, que constituem o objeto do processo. Por isso, o direito não é dado antes do processo, realiza-se no curso do processo, momento em que o caso concreto se manifesta através da linguagem, da oratória, da argumentação.

Assim, a justa proporção entre extremos não é resultado de um cálculo, mas da arte dialética de uma razão comunicativa e expressiva do sofrimento do particular diante das normas gerais da civitas.

\section{5) O direito é cidadão, civium}

Enquanto fenômeno político, dikaion politikon, o direito destina-se a efetuar a partilha de bens e responsabilidades entre cidadãos, civium, ou seja, entre aqueles que se relacionam no espaço extrafamiliar da cidade-estado.

Nesse sentido, o direito não deriva dos laços de sangue, mas dos laços de cidadania. Por não participarem da trama interna da cidade-estado, não tendo, por conseguinte, direitos e obrigações, melhor, compromisso com a comunidade, os estrangeiros, cidadãos de outras cidades, também não são objeto do jus civile.

\section{6) $O$ direito constitui-se de usos e costumes, usitatae}

Instituído pelos fins imanentes à própria realidade social, política e econômica, o direito não pode ser um produto da razão subjetiva. Não é uma constituição jurídica idealista, perfeita, mas a medida da cidadania de um povo. Se este vive à margem da sociedade, é porque seu direito, seus usos e costumes confundem-se com a própria barbárie, com a violência.

\section{7) $O$ direito fundamenta-se em regras e princípios, legitimae}

A cidade-estado é constituída por regras gerais e princípios reguladores da vida dos cidadãos. Constituído a partir dos usos e costumes, estas normas gerais devem orientar a atividade dos jurisconsultos e juízes, evitando que estes analisem ou julguem o caso concreto a partir de regras e princípios sem base na realidade social. Enquanto um fim (telos) derivado do mundo da vida, o direito é digno de respeito, na medida de sua própria realização.

\section{. V. Princípios da ARS JURIS ROMANA}

A partir dessa definição de Cícero, o direito romano edifica-se e ganha contornos axiológicos mais nuançados. Ainda conforme a orientação, coleta e tradução do professor Michel Villey, em seu livro Le droit et les droits de l'homme, penetremos agora no seu âmago, a partir dos textos das Institutas de Ulpiano, contidas no Digesto, uma das obras componentes do Corpus Juris Civilis e a melhor porta de entrada para o conhecimento do direito romano. Eis, a seguir, os princípios desenvolvidos pelos jurisconsultos, a partir das lições republicanas do autor de De oratore, construtor da ponte de ouro que une a filosofia grega à história jurídica de Roma.

\section{1) Princípio da justiça}


Conforme $D, I, I, 1$, Ulpianus, Libro primo Institutionum, selecionado por Villey:

Quem vai trabalhar com o direito deve conhecer de onde vem este vocábulo: 'justiça'. Com efeito, segundo a elegante fórmula do jurista Celso, o direito é a arte do bom e da equidade. Têm razão aqueles que nos chamam profetas da justiça: pois nós cultivamos a justiça, nós pregamos o conhecimento do bom e da boa proporção, operando o discernimento do justo e do injusto. Nós juristas cultivamos a filosofia verdadeira, não seu simulacro verbal. ${ }^{12}$

Vê-se, neste fragmento, a influência da filosofia de Aristóteles. A ideia geral de justiça é contrabalançada pelo peso concreto da coisa justa, que deve ser conhecida, cultivada e ensinada numa comunidade real, para que os cidadãos tenham discernimento, capacidade de identificar se a justa proporção foi ou não foi atingida. $\mathrm{O}$ jurista deve, portanto, ser um sábio, um filósofo, ter como parâmetro a ética, cuja finalidade não é outra, senão educar os indivíduos para se tornarem cada vez melhores no ato de construção da vida coletiva.

Enquanto filósofo, o jurista deve ir às praças, ruas e escolas, tornar pública sua compreensão do direito, pois a razão jurídica não está pronta: embora derivada dos usos e costumes populares, ela só se faz consciência mediante o debate, o exercício responsável da palavra, conforme a tradição do logos grego. O exercício do sacerdócio jurídico não deve degenerar em verborreia estéril, numa espécie de simulacro da dialética.

\section{2) Princípio da atribuição}

Villey destaca a seguinte passagem, encontrada em D, I, I, 10, Ulpianus, Libro primo regularum: "A justiça é uma vontade constante e durável de atribuir a cada um o seu direito"13. Segundo Villey, os romanistas modernos falsificaram esta fórmula, substituindo o verbo tribuere por reddere, como se a dívida de cada um fosse definida na esfera privada. De fato, não se trata aqui de uma dívida, mas de uma atribuição pública dos bens e responsabilidades distribuídos a cada cidadão da civitas, da cidadeestado.

A leitura privatista e individualista do direito romano, utilizada pelos historiadores e juristas do século XIX, tem transformado esta fórmula na insígnia da burguesia proprietária, consagrada nos códigos civis modernos, mediante a figura do direito subjetivo absoluto à propriedade privada. No entanto, a considerar os estudos de Jean-Marie Carbasse, mais de noventa por cento da legislação republicana da Roma antiga era de direito público ${ }^{14}$.

\section{3) Princípio da realização da justiça}

Segundo $D, I, I, 10$, Ulpianus, Libro primo regularum, apontado por Villey: "Jurisprudência é o conhecimento das coisas divinas e humanas, a ciência do justo e do injusto"15. Ou seja, o direito é a realização da justiça no caso particular, isto é, o direito é o justo, jus est ars boni et aequi.

Coerente com as lições de Aristóteles, Ulpianus apenas corrobora a ideia de equidade, pela qual ou o universal se particulariza no meio social, cumprindo suas promessas de encontrar a justa proporção no caso concreto, ou o universal não existe, sendo apenas uma quimera.

Para os romanos, como para Aristóteles, o justo não é uma ideia platônica, perfeita, fora do real. O justo e o injusto são coisas tão divinas quanto humanas, que devem ser conhecidas com distinção e prudência pelos juristas. 


\section{4) Princípio da distinção entre o justo natural e o justo positivo}

A partir da pesquisa de Villey, encontramos este princípio no seguinte excerto de $D, I, I, 2$, Paulo: "Jus se diz de vários modos. Pode designar o que é justo e bom universalmente: tal é o jus naturale; ou o que, numa cidade qualquer, é útil a todos: tal é o direito civil."

Os romanos retomam aqui a distinção aristotélica entre justo em si, dikaion phusikon, e justo civil, dikaion nomikon, proveniente das opiniões e convenções entre homens de determinadas cidades. O justo em si é o homem político, o zoon politikon, que tem disposição natural para a vida em comunidade, para realizar o fim imanente da natureza humana, a saber, o de aperfeiçoar-se. O justo civil, por depender dos usos e costumes praticados nas cidades, é variável segundo os regimes políticos adotados.

Todavia, seja numa democracia ou numa oligarquia, os homens não devem desviar-se da sua disposição de realizar sua finalidade imanente, uma vez que essa não está condicionada à subjetividade. Para Aristóteles, o justo em si é universal, inclui o cosmos e os seres racionais, é a própria ordem das coisas.

\section{5) Princípios da interpretação dos costumes e da produção de regras jurídicas}

Villey nos faz ver em D,I,2,2, Pomponius: "(...) em nossa cidade existem instituições fundadas na lei, mas o direito civil, em sentido próprio, consiste na ausência de toda lei escrita, resultando do trabalho de interpretação dos jurisconsultos"16.

Daqui inferimos que o justo civil não se confunde com as leis escritas, mas com o direito positivo, sendo este o conjunto de regras jurídicas, escritas ou não, derivadas da reflexão de juristas prudentes, cujo objeto são os usos e costumes praticados pela população.

É que, no período arcaico, do século VIII ao século II a.c, o direito romano ainda não era organizado em leis e princípios, o que torna uma falácia a tão propalada separação dos sistemas jurídicos em civil law e common law, como se não tivessem uma origem comum. Em verdade, tanto um como outro se inspiram em épocas diferentes do direito romano. Com efeito, se o common law inspira-se no período arcaico, o civil law inspira-se no período clássico - do século II a.c ao século II d.c - e pós-clássico, a partir do século II d.c.

A interpretação, segundo este fragmento, antecede o momento da circulação das normas e princípios. Isso quer dizer que antes de interpretar leis e regras, é necessário que se interprete os atos socialmente exercidos. Dito de outro modo, interpretar é produzir normas e orientações, tendo como ponto de partida os casos concretos.

Este movimento hermenêutico, que vai do particular para o geral, se opõe ao movimento exegético do dominato. Este, tomado como modelo para a metodologia jurídica do século XIX, parte da apreensão do sentido das leis, para então subsumir-lhe, autoritariamente, os casos concretos.

\section{6) Princípio da distinção entre o justo e o injusto}

Na dicção de D,I,I,I,10 já visto ut supra: "A jurisprudência é o conhecimento das coisas divinas e humanas, a ciência do justo e do injusto"17.

Este fragmento aponta para a ideia de que o direito não é um exercício subjetivo da racionalidade, de onde seriam descobertos pela intuição as normas e princípios reitores da realidade social. O direito é um ato de conhecimento objetivo tanto das situações de injustiça, quanto das situações de justiça. 
Para atingir esse conhecimento, os jurisconsultos devem inserir-se na comunidade, a fim de descobrir os atos praticados pelo povo, que desenvolvem e aperfeiçoam o bem comum. Estes atos já experimentados pelos cidadãos tornam-se regras de orientação para os magistrados e para a comunidade. Os atos que depõem

112 injustos.

O direito é, portanto, uma sorte de memória de exemplos coletivos, e os juristas, perscrutadores de normas e princípios de bem estar social. Como nota Villey:

Le métier juridique n'est pas déduction opérée à partir des imperatives. Il est travail de connaissance. Le Dikaion est lui-même chose que le juriste devra découvrir par l'observation d'exemples empruntés à la réalité sociale, plus souvent 'injustes' que justes - qui pour la plupart dévient de la justice ${ }^{18}$.

Outrossim, essa inserção dos jurisconsultos na comunidade não se dá sem controvérsias, sem discussões de situações concretas. Cada caso é, por conseguinte, uma causa, uma oportunidade de fazer avançar o desenvolvimento político da comunidade. Em suma, a tríade distinção-inserção-discussão torna a razão jurídica uma razão participativa e comunicativa, no sentido definido por Habermas em sua teoria da ação comunicativa ${ }^{19}$.

\section{7) Princípio da anterioridade do direito à regra}

Encontramos, com Villey, esta diretiva em D, 50, 17, I, Paulo, segundo o qual: "A função da regra é a de descrever brevemente uma realidade. Não é o direito que nasce da regra; é esta que nasce do direito que já existe" 20 .

Sendo o direito uma realidade, rem, a regra jurídica não deve ser mais do que uma expressão dessa realidade. Por isso, a regra será sempre imperfeita, um modelo geral que, devido a sua dependência ao referente ôntico, não se basta a si mesmo. Dito de outro modo, a regra é relativa, não podendo ser o centro do sistema jurídico.

Por conseguinte, o jurisconsulto deve colocar a regra sob suspeita permanente. Assim, como assinala Villey: "les règles juridiques ne sont pas le droit; elles décrivent le droit. Le droit est chose qui leur préexiste (jus quod est), objet de recherche permanente et de discussion dialectique, à laquelle ne coïncideront jamais nos formules" 21 .

\section{8) Princípio da discussão}

De acordo com $D, 50,17,202$ : "Toda definição do direito é aleatória, presta-se a ser refutada". Na contramão da apreensão autoritária do direito romano pelos juristas do século XIX, que se inspiraram na Roma imperial, este princípio acentua a controvérsia, a dialética da argumentação como fator marcante da realidade jurídica.

A Roma republicana, fortemente influenciada pela democracia grega, desenvolve a arte jurídica como uma arte da eloquência, pautada na participação apaixonada dos jurisconsultos, advogados dos bens e responsabilidades dos cidadãos da urbis. Nesses termos, segundo Villey, estamos diante de uma concepção de direito "(...) qui ne tombe pas d'en haut; ne découle pas d'un souverain, d'une doctrine de théologiens ou de moralistes, ni ne s'enferme pas dans les lois."23

\section{DiReito Romano COMO CRÍTICA AO DIREITO MODERNo}




\section{Apropriação burguesa do direito romano}

Do exposto, já devemos ter percebido que essa abordagem do direito romano não tem nada a ver com o que se espera de um tratamento da matéria em nossas faculdades. Pois, para estas, o direito romano deve ser tratado como mera introdução ao direito moderno, ou melhor, menos que isso, ao direito civil.

Note-se também que esse estudo não se presta a ornamentar discursos de juristas e advogados de nosso tempo, que, em sua maioria, utilizam máximas latinas apenas para reforçar seu desejo de parecer-se com os jurisconsultos romanos, disparando por todos os cantos sua falsa erudição, como se o direito romano fosse uma mera ilustração dos conceitos aprendidos pelas doutrinas universitárias do direito. Magistrados, por sua vez, utilizam-se da fase imperial da velha Roma como modelo de vida, usufruindo de uma falsa identificação com os imperadores, impondo o poder negro de suas togas aos plebeus de nosso tempo, como se ainda fôssemos subjugados à Rex e aos seus ritos e imagens. Em uma palavra: o direito romano tem servido apenas para reforçar o autoritarismo de grande parte dos operadores jurídicos de nosso tempo, que parece ainda não terem percebido que a ars juris republicana da velha Roma era inspirada no modelo democrático da Grécia antiga, bem como na melhor linhagem filosófica pagã, que considerava o homem como um animal político, um zoon politikon.

A fase imperial, a fase decadente da Roma antiga, tomada como modelo por nossos operadores jurídicos é a fase autoritária, do poder absoluto das normas gerais, impostas a cada cidade conquistada pelo império romano, à revelia dos usos e costumes praticados por novos súditos incorporados ao império à força das armas. Mas por que os operadores jurídicos da burguesia se valeram desse modelo autoritário para ilustrar seu modo de vida imperial? Puro capricho? Ou porque de fato sua ideia de democracia era apenas um simulacro?

Ora, no final da Idade Média de que serviria utilizar-se de um direito democrático, como o republicano da Roma antiga, para expulsar os camponeses de suas terras, obrigando-os a servir de mão de obra livre e desimpedida para ser submetida aos meios de produção da burguesia, ou seja, às suas corporações de ofício, manufaturas e fábricas? De que valeria um direito romano aberto ao diálogo com o caso concreto, como era a ars juris dos primeiros jurisconsultos, inspirados na filosofia aristotélica, para destruir famílias e comunidades inteiras, a fim de obrigar seus membros a servirem fielmente aos seus novos patrões, em troca de um mísero salário? Em suma, de que serviria a ética jurídica de Cícero para impor a violência, o saque, o derramamento de sangue tanto às comunidades agrárias da velha Europa, como às novas terras conquistadas da Ásia, África e América?

Em verdade, o direito romano da fase republicana não iria servir para esses propósitos capitalistas. A burguesia, que nunca foi culta e que nunca teve bens, a não ser o lixo do espólio das monarquias ocidentais e orientais e as quinquilharias oferecidas nas feiras das primeiras cidades medievais, precisava dar um duplo golpe: apropriar-se dos meios de produção do conhecimento e de toda a propriedade da terra. Este anseio imperialista só poderia ser justificado com o mau uso dos tesouros de sabedoria que a humanidade havia produzido. Para o saque, era preciso uma cultura do saque, e esta não poderia ser buscada senão na cultura totalitária do imperialismo romano, modelo ideal de dominação que havia dado certo.

No entanto, essa cultura do saque deveria prestar-se não só à dominação dos corpos, mas também à subjugação das almas. Se a cultura imperialista romana servia de modelo para a dominação dos corpos do mundo, qual deveria ser o modelo para a dominação das almas? O modelo católico da Idade Média, que tornou sagrado o exercício da Rex. Foi com esse modelo romano-canônico que a burguesia se armou para o saque do planeta e de seus habitantes. Estavam dadas, então, as condições subjetivas 
para que essa burguesia comerciante pretendesse tornar-se dona do mundo e dos espíritos que o habitavam. Com efeito, o mundo do capitalismo comercial e industrial, símbolo do latrocínio, do genocídio e da ignorância, tornou-se modelo para os humanos. A ele submeteram-se os togados, seus sacerdotes; e sua religião, o direito imperial, foi ensinada às vítimas do saque.

Após esse período de acumulação primitiva, juristas europeus deram os primeiros contornos aos direitos e liberdades fundamentais - como o direito de propriedade, direito ao ensino público, direito à dignidade, à liberdade, à fraternidade, etc. -, cujos beneficiários jurídicos eram os próprios beneficiários econômicos. Mas, se os saqueados foram desapossados de toda a sua Res, o que lhes sobrou? Um direito sem res, sem coisalidade, sem conteúdo, sem corpo, sem alma: o direito subjetivo, um fantasma, uma promessa cristã, manifestação de piedade àquelas vítimas e testemunhas da violência inaugural do mundo moderno.

Isso explica o ódio manifestado pelos camponeses, no final da Idade Média, a padres e juízes. Assim, é como se a imagem de um togado transmitisse o seguinte discurso aos despossuídos, condenados da terra: "Tu nada tens, mas te dou o direito subjetivo, para que pelo menos possas crer que ainda és um humano, pois preciso de ti, do fantasma do teu corpo e de tua alma, para meu deleite". E se o desgraçado ousasse responder: "Tudo bem, já tens meu corpo e minha alma, já não basta?". O sacerdote do Capital replicaria: "Agora, quero sua obediência, pois com ela reafirmas com tua boca e teus gestos de escravo que és um nada e que nada sempre serás".

\section{2) O direito romano como direito concreto}

Vimos acima que, para Aristóteles, o direito ou é uma res ou não é direito, isto é, ou há uma partilha de bens e funções na comunidade ou não há o dikaion. Melhor, ou o direito é objetivo ou não é direito, pois este não é potência, intenção, promessa, mas ato, fato e atualidade, razão pela qual, como destaca Villey, não havia direito subjetivo na Roma antiga. As Institutas de Gaius, descobertas em 1816 pelo alemão Niebuhr, redigidas no século II d.c - segundo Villey "le seul ouvrage de droit classique dont on ait conservé l'ensemble; devenu le texte de prédilection des spécialistes du droit classique" -, dividia a matéria jurídica em Pessoas, Coisas e Ações. Mas o termo pessoas aqui indicava persona, um papel, uma função exercida na comunidade.

Podemos perguntar, com Villey: onde a noção de pessoa, de direito subjetivo no direito romano? Onde o poder de agir, a força imperial da vontade do sujeito sobre o mundo (Willesmacht), tão celebrado pelos juristas do século das luzes? As Institutas de Gaius não tratavam do homem como ser isolado, hipostasiado da sociedade; elas se dividiam, com efeito, em três títulos: pessoas, coisas e ações, seguindo o plano de Cícero, para quem o direito civil é in rebus causisque civium, conforme vimos. Podemos perceber que as pessoas estão aqui situadas no contexto, dentro de uma relação social determinada, onde pessoas determinadas disputam coisas determinadas, por meio de ações determinadas e numa determinada época. Por isso, tem razão Villey quando denomina a obra de Gaius de uma sociologia não neutra, ou seja, uma quasesociologia, avessa, avant la lettre, às abstrações que impregnaram a escola jusnaturalista racional moderna. Como obra realista, portanto, o manual de Gaius refere-se a pessoas, coisas e ações no plural. As definições gerais (gêneros) surgem a partir da diversidade de espécies, sem perderem o contato com o mundo concreto.

Isso quer dizer que as definições jurídicas contidas no Digesto, livro I, título I, já implicam a relação com as espécies de direitos, assim como, para Aristóteles, a palavra dikaion implicava seu plural, ta dikaia. Mas, quais são as espécies de direitos? Segundo Villey, são elas: jus naturale, jus gentium e jus civile. Por jus naturale, devemos 
compreender um conjunto de relações jurídicas entre seres animados, humanos e não humanos, como indica a fórmula de Ulpiano, (D,I, 1,1): "Maris atque feminae conjunctio... liberorum procreatio, educatio...". Como vemos, simplesmente um escândalo para o jusnaturalismo moderno.

Por jus gentium, define-se o direito da convivência de cidadãos provenientes de cidades diversas dentro da velha Roma. Por isso, esta espécie teve tanto uso na fase imperial, quando Roma expandiu suas fronteiras políticas, sociais e econômicas para o resto do mundo. Estavam contidos nessa espécie deveres de piedade, de obediência aos pais, de resistência às agressões externas, de estabelecer contratos internacionais. É, como vimos, uma espécie problemática, devido à dificuldade de se firmar um terceiro desinteressado nas relações entre cidades soberanas. Esta vulnerabilidade política do jus gentium o descaracteriza, a rigor, como direito, dikaion, se temos em mente as lições de Aristóteles.

O jus civile, por sua vez, é o jura populi romani, a pluralidade dos direitos dos cidadãos romanos, inscritos em leis, plebiscitos, sentenças, constituições e outros tipos normativos. Menos geral que o jus naturale e mais político que o jus gentium, o jus civile é a própria ars juris projetada por Cícero, expressão máxima do direito clássico.

Essa relação entre gênero e espécies, entre o que é justo em geral (id quod justum est) e o justo em particular, ou seja, jura, diversidade de figuras jurídicas particulares, está bem estabelecida na relação entre o Digesto e as Institutas de Gaius. A infinidade de casos concretos não pode, portanto, ser esquecida pela jurisprudência, a qual não é mais que uma notitia rerum, uma notícia de casos de relevância jurídicopolítica, de jura, sem o que a cidade não se sustenta politicamente.

Nesse sentido, a justiça, tendo como objeto o jus suum cuique tribuere, é antes parte do que partilha, melhor, é antes a coisa em seu estatuto singular, já atribuída a pessoas singulares, dentro de uma rede de relações estabelecidas na cidade, do que a coisa com a vocação de ser parte, ou seja, como promessa de partilha, ou como parte abstrata. Para ficarmos no exemplo de Villey, de um lado temos o direito à terra, jus fundi, direito agrário, abstrato, promessa de partilha e, por conseguinte, um mero nãoser; de outro temos a situação concreta das relações entre pessoas e terras, os jura praediorum, a parte já atribuída, ou seja, o próprio direito, que se confunde com sua existência, ser ser-aí.

Nesse sentido, as Institutas não estabelecem regras de conduta, um dever ser, mas descrevem o enredo da comunidade, onde pessoas reais, livres, escravos, mulheres, crianças, adultos, disputam coisas reais, a partir de ações reais. Na medida em que a comunidade efetua a partilha de bens, funções e responsabilidade às pessoas, estas jamais poderiam ser consideradas como categoria anterior e superior à sociedade. Pessoas e Coisas pertencem a uma mesma ordem natural, onde predomina a relação horizontal, não a hierarquia, ou seja, pessoas e coisas estão no mesmo nível.

Vê-se, portanto, que, diferentemente do direito moderno, no direito romano como conservando, por assim dizer, a astúcia pré-socrática - as coisas são também dignas de respeito, pois foram atribuídas pela ordem cósmica às comunidades e, pela comunidade política, às pessoas, não podendo, consequentemente, ser abandonadas ao uso, abuso e usufruto, como se fossem produtos absolutamente disponíveis ao homem. Se os juristas da burguesia tratam as coisas como valor de troca, os jurisconsultos romanos ressaltavam o valor de uso das coisas, assegurando assim que as coisas não fossem objeto de destruição por quem as detivesse.

Assim, na Roma antiga, em cada coisa estava impressa uma finalidade natural, a qual não poderia ser desviada, sob pena de infringir-se o dikaion phusikon. Num movimento oposto à abstração dos modernos, que transforma as pessoas em sujeito e as coisas em valor de troca, o mundo antigo colocava em evidência a qualidade de pessoas e coisas. $\mathrm{O}$ contato com o mundo sensível causava a percepção das diferenças entre 
pessoas e coisas. O mundo pagão era, portanto, o mundo da pluralidade de pessoas, coisas e deuses, estes inseparáveis das formas da natureza. Por isso, como sugere Villey, Aristóteles não escreveu uma ética, sua obra deveria ser traduzida como "Éticas à Nicômaco", assim como ao lado do termo dikaion, o estagirita usava também ta dikaia, direito ao plural, ou seja, o direito organizado posteriormente pelo Digesto em três categorias, jus naturale, jus gentium e jus civile, como vimos.

\section{3) A dimensão horizontal e vertical do direito romano}

Mas se o direito romano se opõe ao direito abstrato, subjetivo, não podemos confundi-lo simplesmente com as coisas corpóreas, como cadeira, casa, mesa, caneta. Pois se direito é res, não uma res qualquer, e sim uma res justa, ou seja, a própria relação entre pessoas, bens e responsabilidades no âmbito de uma comunidade política.

Assim, o direito não se restringe a uma relação isolada entre pessoas e bens, reinando aquelas sobre estes, acima de qualquer agrupamento social. A verticalidade entre o anthropos e o cosmos, de um lado, e de outro entre anthropus e societas, tão celebrada pela filosofia moderna não era uma verdade para gregos nem para os romanos. A horizontalidade entre estas esferas aponta para um modelo de relação jurídico-política, na qual todos estão implicados. Quer dizer, o direito não é a casa, mesa ou cadeira, mas a relação que as pessoas estabelecem com elas, conforme a atribuição da constituição política. Desse modo, não é porque tenho uma casa que posso abusar dela, extrapolando sua função, seu sentido social. Não é porque possuo cinco canetas, que tenho o direito de jogá-las ao lixo. Comprar duas mil cadeiras ou mesas para queimá-las é um ato violento, pois não há relação possível nesse ato. Enfim, horizontalidade da relação jurídica significa respeito para com coisas e pessoas.

A relação entre anthropos e cosmos é histórica, isto é, muda de acordo com a época a que nos referimos no mundo antigo. Se a filosofia pré-socrática ressalta a dimensão da physis, na qual todos os seres participam igualmente da ordem cósmica e gozam de espiritualidade, de alma, no período socrático, há uma forte tendência à hierarquização da relação entre os homens, dotados de razão, e os outros seres.

A filosofia aristotélica alberga essa contradição, diga-se de passagem, uma contradição objetiva, na qual o lugar do homem no mundo natural é bastante relativizado. Com efeito, escravos, crianças e mulheres sofrem dessa influência socrática, principalmente na obra de Aristóteles. Mas essa mitigação da dimensão cosmológica na obra do estagirita não é total, como o demonstra sua ética, onde a ideia de finalidade dos homens é resultado de um raciocínio analógico que parte da finalidade das coisas.

Essa contradição, por exemplo, está presente na própria ideia de escravo, um ser ao mesmo tempo pertencente à ordem natural das coisas e acima dela, ou seja, um ser racional e deliberante, que goza do estatuto de ser superior, podendo comandar seres inferiores. Também se manifesta, de modo menos evidente, na relação entre direito natural e direito positivo na Ética a Nicômaco, em que Aristóteles tenta compatibilizar a ordem da convenção com a ordem da natureza. Ela é aprofundada no estoicismo, que eleva o horizonte da razão ao paroxismo, a ponto de identificá-la com a própria ordem universal e divina. Assim, o homem, conceito universal, independentemente de sua condição na sociedade, passa a encarnar a razão divina; nas palavras de Cícero: Est igitur homini cum Deo similitudo (De legibus, I, 8).

Em suma, aos poucos, a dicotomia entre razão e natureza se aprofunda a partir da filosofia socrática até atingir o ponto de ruptura no cristianismo, em que razão e natureza passam a se opor implacavelmente. Nesse momento, a relação horizontal entre anthropos e cosmos é totalmente submetida à hierarquia entre espírito e matéria. $\mathrm{O}$ 
direito romano se situa, portanto, na conjunção tensa entre três paradigmas, a saber, o cosmológico, o antropológico e o teológico, sendo que o período republicano ou clássico pode ser entendido como produto da tensão entre os dois primeiros, com dominante antropológica, que será hegemônica na fase imperialista, momento em que o mundo oriental e ocidental passam a subordinar-se ao poder pessoal da Rex romana. Com a ascensão da igreja, após a derrocada do império romano, até o advento do absolutismo, a realeza passa a encarnar a tensão entre as dimensões antropológica e divina, com dominante divina, momento em que os imperadores, apesar de obrigarem os súditos a adorá-los como deuses, entram em conflito permanente com o poder eclesiástico. Essa tensão torna-se expressa na célebre afirmação de Cristo: "A Deus o que é de Deus; a César o que é de César". Com efeito, a Idade Média representa o momento da transubstanciação completa da rex em Deus, este o poder supremo a quem tudo e todos estão submetidos. É quando o direito romano se torna canônico.

\section{4) O direito romano como forma contraditória}

A forma jurídica romana não é, por conseguinte, uma forma coerente e harmônica, como querem nos fazer crer não poucos romanistas. Pelo contrário, ela alberga já as grandes tensões da filosofia jurídica como direito natural/direito positivo, caso concreto/norma geral; ou da filosofia política, como república/império; ou da própria filosofia, como razão/natureza, particular/universal; ainda da sociologia, como local/global.

Ao lado de uma tendência autoritária e imperial de desprezo pelo caso concreto, o direito romano manifesta uma dimensão não metafísica, avessa ao espírito geométrico, expressa no primeiro fragmento do Digesto por Ulpianus como "veram, non simulatam philosophiam". Essa veram philosophiam caracteriza-se por sua imanência, por sua concretude, ou, como diria o filósofo alemão Adorno ${ }^{23}$, por seu teor coisal (Sachhaltigkeit), em oposição à simulatam philosophiam, em que o jus degenera em lex, a lex em rex, esta em Deus e o local em global, espaço-tempo de um homem universal que rejeita cada vez mais a dimensão particular da existência.

Com efeito, como nos ensina Villey, a moral romana era uma mônada composta de uma constelação de ideias, a saber, a universalidade de uma lei comum não escrita (nomos koinos), deveres concretos (De Officiis) como a humanitas, a benignitas, a caritas, a fides, a pietas e a hospitalitate. Essa constelação de ideias não era mais que uma constelação de atitudes já praticadas e observadas pelos filósofos na comunidade, ao lado de atitudes nocivas à sobrevivência da polis.

A Ethika romana, portanto, como seleção de bons costumes (boni mores), era pragmática, uma espécie de trigo separado do joio dos maus costumes, e não uma criação subjetiva, abstrata, sem conteúdo social. Uma vez descobertos, os boni mores eram objeto de especulação filosófica, onde deveriam ser socraticamente defendidos ou atacados e firmado seus fundamentos. Estes, mediante a educação e um ideal estoico de universalidade, deveriam conquistar todos os povos. Infelizmente esta consigna estoica é interrompida pelo autoritarismo da fase imperial do direito romano: Justiniano, por decreto, tenta acabar com a tradição dialética ao mandar fechar as últimas escolas filosóficas gregas.

Esse conflito entre o poder do Um e o poder do Múltiplo, entre o poder imperial e o poder republicano, entre a autoridade da rex e a autoridade da polis, é uma marca da forma ético-jurídica romana, possível causa da confusão entre o convencional e o natural, entre lex e jus; causa também da polissemia do termo justiça, traduzida por uns como retidão, ordem e por outros como justa proporção, como vimos.

Entretanto, contido no plano de uma moral concreta, o direito é bem menos que 
esta, sendo apenas um justo meio, uma distribuição de recompensas e penas a quem pratique os bons costumes ou ameace o bem comum. Nesse sentido, o direito só é lex enquanto inscrito na esfera do jus, ou seja, não pode ser partilha de um nada para ninguém. Melhor, a finalidade do direito é sempre política, no sentido aristotélico, vale dizer, é um telos ético.

É claro que essa conjunção da moral com o direito é objeto de um movimento contrário, em que a lex é preenchida de sentidos pela rex, pelo autoritarismo impaciente dos imperadores, causando, então, uma tensão polissêmica e objetiva na relação entre direito e moral. Assim como a conduta é tensionada, o direito também o é. Tanto o direito como a moral tornam-se uma forma contraditória, em que suas linhas de força são demarcadas de um lado pela violência, de outro pelo bem comum.

De uma parte, temos os sujeitos determinados com atitudes boas ou más para a comunidade; de outra e respectivamente, a partilha da justiça ou da injustiça, ou seja, a distribuição de bens, responsabilidades e funções (partilha positiva) ou a distribuição de atos de violência, tais como o saque, a hostilidade, a perseguição, a intolerância e o ostracismo (partilha negativa).

Desse modo, tem razão Villey quando afirma que, diferente da moral, cuja finalidade é o aperfeiçoamento de virtudes, no direito não existem sujeitos, mas agenciamentos de bens, responsabilidades e funções, ou mais precisamente, o direito é constituído por relações entre sujeitos, e essas relações são coisas exteriores atribuídas ou agenciadas pela comunidade ético-política a seus cidadãos.

Acrescentamos: o direito é também o contrário disso, vale dizer, é a assunção sagrada e vertical do poder pessoal, em detrimento da intersubjetividade. Por isso, a origem do conceito de sujeito de direito é despótica, pois tal conceito não estabelece a relação sinalagmática com o outro, um sujeito sem obrigações, portanto.

A percepção moderna do direito, com ênfase na figura do sujeito, não é mais do que a imitação dogmática do poder da consciência autossuficiente, em detrimento da comunicabilidade entre os indivíduos. A mística de um sujeito sem obligatio é a mística de uma liberdade sem condicionamentos, absoluta e autoritária, porque imune às relações e ao argumento.

Do exposto, podemos formular a seguinte aporia, pondo uma nova luz sobre a querela entre antigos e modernos: a forma jurídica é, sincronicamente, clássica e não clássica, intersubjetiva e subjetiva, concreta e abstrata, uma veram philosophiam e uma simulatam philosophiam. Sua complexidade advém de ser uma forma contraditória sem síntese, uma forma trágica, resistente ao conceito e à lógica dedutivo-formal, incapaz de pensar ideias contrapostas. Melhor, o campo de força clássico da forma jurídica é composto das seguintes linhas, que se opõem frontalmente ao campo de força não clássico: a) objetividade; b) tributariedade; c) diferença; c) equidade; d) pluralidade; e) dialética; f) proporcionalidade; g) determinabilidade; h) particularidade; i) horizontalidade; j) comunicabilidade e k) heteronomia. Tais categorias dão à forma jurídica um forte teor mimético, na medida em que aproximam o direito do caso concreto, possibilitando o diálogo do universal com o particular.

No contexto da Roma republicana esse campo de força é dominante, porém, à medida que a realeza se impõe, a ruptura com o caso concreto - com a dimensão individual das situações jurídicas -, torna-se a regra. A comunicação entre a norma geral e a esfera individual é substituída pelo poder prescritivo daquela sobre esta, ao mesmo tempo em que a categoria da comunicação é substituída pela categoria da subsunção. Porque a relação profana entre os cidadãos e o Estado torna-se cada vez mais sagrada, o argumento, a discussão e o debate são eliminados das praças públicas, substituídos pelos rituais palacianos de submissão dos cidadãos aos imperadores.

Em suma: a dialética degenera em liturgia. As relações jurídicas verticalizam-se, ao mesmo tempo em que perdem sua fisionomia, sua particularidade. Isso ocorre, 
talvez, devido à expansão imperialista romana, cuja força militar encarna a figura de um poder ausente, operando à custa de emissários e burocratas autoritários, cegos diante da diversidade de culturas e incapazes de articularem julgamentos justos diante dos casos concretos. Nessa situação de incomunicabilidade, a impaciência da norma se impõe implacavelmente e o poder sagrado do Um corrói todas as chances de aperfeiçoamento da democracia e das instituições republicanas.

\section{CONCLUSÃo}

O sentido republicano da velha Roma, segundo o qual o direito só se realiza no encontro com o homem particular e com o caso concreto, pode ser atualizado em nosso tempo. No diálogo permanente entre a norma e o fato social repousa a possibilidade de recuperarmos a ideia grega de responsabilidade pelos negócios da cidade. Sendo cada cidadão um animal político, não há porque delegarmos a responsabilidade do empreendimento humano a uma figura abstrata, artificial e originariamente irresponsável como o Estado-Leviatã e toda sua ciência política. A recuperação hodierna dos valores republicanos passa pela superação da pré-história da economia e da política, até agora grosseira técnica de dominação e empecilho crucial para a realização das promessas de direitos e garantias fundamentais, condensados nas constituições contemporâneas.

Nesse sentido, a releitura do direito antigo traz consigo toda a sua força crítica, como se o passado, resistindo ao esquecimento, se pusesse a exigir a prestação de contas de um presente que, embora vitorioso no âmbito da razão teórica, não conseguiu desenvolver minimamente a razão prática, a considerar o atual estado de miséria social dos povos e de destruição do planeta. Enquanto os direitos humanos continuarem sem rosto e sem corpo, ou seja, sem aesthesis, não poderão atrair para si a densidade conceitual do dikaion, cuja potência epistemológica exige, para seu florescimento, o ato criativo de conjunção de interesses entre o homem e a natureza.

\section{REFERÊNCIAS}

ADORNO, Theodor W. Dialectique négative. Paris: Payot, 1992

ARISTÓTELES. Ética a Nicômaco. São Paulo: Abril Cultural, 1973.

CICERONIS, M. Tulli. De oratore, Liber Primus, XLII, 188, (http://www.thelatinlibrary.com/cicero/oratore1.shtml).

CARBASSE, Jean-Marie. Manuel d'introduction historique au droit. Paris: Puf, 2002.

HABERMAS, Jürgen. Théorie de l'agir communicationnel. Paris: Fayard, 1987.

LOPES, Luís Sérgio. Causalité et Liberté: Implications Juridiques de l'Esthétique d'Adorno, ANRT, Université de Lille III, 2016.

SATIE, Luis. Teoria estética do direito. Rio de Janeiro: Cbje, 2008.

SATIE, Luis. Mínima estética Jurídica: Lineamentos para a nova faculdade de julgar. Rio de Janeiro: Cbje, 2009.

VENOSA, Sílvio de Salvo. Direito Civil. São Paulo: Atlas, 2009.

VILLEY, Michel. Le droit et les droits de l'homme. Paris: Puf, 1998.

VILLEY, Michel. Philosophie du droit. Paris: Dalloz, 1975.

VILLEY, Michel. Le droit romain. Paris: Puf, 1957.

\section{Notas}

1 Ver LOPES, Luís Sérgio [Dit Luis Satie]. Causalité et Liberté : Implications Juridiques de l'Esthétique d'Adorno, ANRT, Université de Lille III, 2016. Ver também SATIE, Luis. 
Teoria estética do direito. Rio de Janeiro: Cbje, 2008 e Mínima estética Jurídica: Lineamentos para a nova faculdade de julgar. Rio de Janeiro: Cbje, 2009.

2 VILLEY, Michel. Le droit et les droits de l'homme. Paris: Puf, 1998.

3 CARBASSE, Jean-Marie. Manuel d'Introduction historique au droit. Paris: Puf, 2002.

4 CARBASSE, op. cit., p. 16: "Em cada época as diversas manifestações do direito formam um sistema, um conjunto coerente. Para compreender cada um desses momentos, recomenda-se não quebrar esta coerência".

5 VILLEY, op. cit. p. 9: "sua função foi a de legitimar, sob o capitalismo liberal, excessivas desigualdades, que se perpetuam em numerosas regiões do globo, e, diversamente acentuado segundo os países e as épocas, a sujeição ao Poder".

6 In verbis: "eis a finalidade do direito: conservar a equidade nas disputas entre os cidadãos". Ver Cícero. De oratore, XLII, 188, http://www.thelatinlibrary.com/cicero/oratore1.shtml.

7 Ver ARISTÓTELES. Ética a Nicômaco. São Paulo: Abril Cultural, 1973.

8 VILLEY, op. cit., p. 49: "Se o direito é coisa ou parte de coisa, ele não se confunde com uma 'liberdade'; quando muito, a parte de cada um constitui sempre um misto de ativo e passivo; cada vez que um cidadão se vê atribuir uma propriedade, ele deve suportar também as responsabilidades que lhe correspondem".

9 Ibidem, p. 52: "os direitos reconhecidos às diversas pessoas serão desiguais. Quanto mais a justiça se aproxima da equidade perfeita, mais ela, provavelmente, resultará na desigualdade de direitos".

10 Ibidem, p. 54: "Segundo a análise de Aristóteles, o direito é descoberto pela observação da realidade social, bem como pelo confronto de pontos de vista sobre esta realidade; porque o direito, objeto da justiça, no sentido estrito do termo, é precisamente este meio, a boa proporção das coisas partilhadas entre os membros do grupo político".

11 Ver, por exemplo, VENOSA, Sílvio de Salvo. Direito Civil. Atlas, 2009.

12 In verbis: "Juri operam daturum prius nosse oportet unde nomen juris descendat - est autem a justitia appelatum: nam, ut eleganter Celsus definit, jus est ars boni et aequi. Cujus merito quis nos sacerdotes appellet. Justitiam namque colimus et boni et aequi notitiam profitemur, aequum ab initio separantes licitum ab illicito discernantes...veram nisi fallor philosophiam, non simulatam affectantes".

13 In verbis: "Justitia est constans et perpetua voluntas jus suum cuique tribuendi: I. Juris praecepta sunt haec: honeste vivere, alterum non laedere, suum cuique tribuere".

Carbasse, op. cit., p. 19.

15 In verbis: "Jurisprudentia est divinarum atque humanarum rerum notitia, justi atque injusti scientia".

16 In verbis: "Aut est proprium jus civile, quod sine scripto in sola prudentium interpretatione consistit".

17 In verbis: "Jurisprudentia est divinarum atque humanarum notitia justi atque injusti scientia".

18 VILLEY, op. cit, p. 66 ("O ofício jurídico não é dedução operada a partir de imperativos. É trabalho de conhecimento. O Dikaion é coisa que o jurista deverá descobrir pela observação dos exemplos emprestados à realidade social, mais frequentemente 'injustos' que justos - os quais na maioria das vezes se desviam da justiça").

19 Ver HABERMAS, Jürgen. Théorie de l'agir communicationnel. Paris: Fayard, 1987.

20 In verbis: "Regula est quae rem quae est breviter enarrat. Non ex regula jus sumatur sed ex jure quod est regula fiat".

21 VILLEY, op. cit, p. 67 (“As regras jurídicas não são o direito; elas descrevem o direito. O direito é coisa que lhes pré-existe (jus quod est), objeto de pesquisa permanente e de discussão dialética, com o que nunca coincidirão nossas fórmulas").

22 Ibidem, p. 68 ("que não cai do alto, nem decorre de um soberano, de uma doutrina de teólogos ou de moralistas, nem se fecha em leis").

23 Sobre os conceitos metodológicos, aqui utilizados, de teor coisal, constelação e campo de força, ver ADORNO, Theodor W. Dialectique négative. Paris: Payot, 1992, p. 160-164. 